\title{
Implications of the New Framework for Market Abuse in the EU*
}

\author{
Lubomír Čunderlík** \\ * The article is the output of VEGA project No. 1/0907/16 "Legal Protection of Parties of Economic and Legal Relations with \\ Emphasis on Criminal-law Protection of Creditors". \\ ** JUDr. Lubomír Čunderlík, PhD., associate professor at the Department of Financial Law of the Faculty of Law, Comenius \\ University in Bratislava; member of supervisory board of Bratislava Stock Exchange, member of the board of Centre for Legal Aid, former \\ director of Banking Department of Ministry of Finance (e-mail: lubomir.cunderlik@flaw.uniba.sk)
}

Abstract: The Market Abuse Regulation (MAR) was adopted in April 2014, and it has been uniformly regulating the issues of insider dealing and market manipulation throughout the EU since 3 July 2016. Unlike the previous legislation, deviation from the regulation's wording will not be possible. This should exclude different applications, which have occurred in the individual EU Member States so far, when investigating unlawful behaviours marked as market abuse. The regulation introduced several substantial changes.

Keywords: market abuse; insider dealing; market manipulation; administrative and criminal offences

\section{Introduction}

Market abuse is considered to be one of the most dangerous unlawful behaviours on the financial market although it is usually referred to as victimless crime. The root of this is favouring certain group of investors with access to non-public information (insiders) or dissemination of false and misleading information within the investing public. Accordingly, we distinguish two basic forms of market abuse: insider dealing and market manipulation. The European Commission assessed the existing regulatory framework for market abuse under the Market Abuse Directive 1 and related implementing directives as insufficiently effective. 2 After ten years of existence and application of the given directive, a new legislation was adopted in the form of regulation on market abuse. 3 Its wording also takes account of the related new legislation on provision of investment services and technological developments on the financial market. 4 Parallel to this legislation a new directive (MAD II) was adopted, harmonizing criminal penalties in the area of market abuse. Criminal law measures can be considered an element to ensure the effective enforcement of EU policies, as recognized by the Treaty on the Functioning of the EU.5

The purpose of the regulation (MAR) is to minimize the national differences in investigation of insider dealing and respective sanction regimes. The regulation entered into force on 3 July 2016, and from this date it repealed MAD and related implementing directives (including the regulation establishing exemptions for buy-back programmes and stabilization of financial instruments). The adoption of the regulation will ensure unification of this issue as well as direct effect of its provisions, and adoption of a national legislation, which may vary across countries, will not be required.

The purpose of the article is to analyze the fundamental changes introduced by MAR compared to the previous European legislation. Several institutes were adopted from the market abuse directive and related implementing directives in the respective regulation, whereas its wording includes also experience from practice or case law of the European Court of Justice.

\section{Substantive Changes Included in MAR}

The regulation contains several changes, $\underline{6}$ some of them are of only legislative and technical nature, and others assume significant impact on more efficient investigation of unlawful conduct such as insider dealing and manipulative practices on the capital market (market manipulation). In the following paragraphs we will try to analyze and summarize the most important changes through some comments. We believe that identification of the most important changes is beneficial not only for the theoreticians of the financial market, but also for the legal practice of the supervisory authority of the capital market.

1. The regulation formally distinguishes, unlike MAD, three types of unlawful conduct as an administrative offence in the field of market abuse: a) insider dealing, b) unlawful disclosure of inside information, c) market manipulation.Z Unlawful disclosure of inside information was subordinated to actions under letter a) in MAD.

2. The material scope as well as the personal scope of prohibition related to market abuse was extended, namely by alternative trading platforms and their participants. The MAD was applied only to financial instruments admitted to 
trading on a regulated market, or for which a request for admission on such market and its derivatives has been made. On the contrary, the regulation includes also financial instruments traded on multilateral trading facilities (MTFs) which were admitted to trading on MTFs or for which a request for admission to trading on MTFs has been made, and financial instruments which are traded on organised trading facilities (OTFs $\underline{8}$ ) and their derivatives2. The reason is the increase in trading volume also on the given alternative trading platforms. In this connection, the personal scope was extended by issuers of such financial instruments with regard to the obligations arising from the market abuse regulation.

3. The personal scope covers also those persons who act in collaboration to commit market abuse.10 In practice it most commonly refers to brokers who devise a trading strategy designed to result in market abuse or persons who encourage a person with inside information to disclose that information unlawfully, or persons who develop software in collaboration with an investment firm for the purpose of facilitating certain forms of market abuse.

4. According to the regulation, the concept of financial instrument will include also emission allowances or auction products based thereon traded on an auction platform with status as a regulated market. The emission allowances were included into the financial instruments already by the adoption of previous Markets in Financial Instruments Directive (MiFID).11 From practical experience, a behaviour which has effect on benchmarks, subject to fulfillment of conditions set out, is also understood as market manipulation according to the regulation. 12

5. In addition to the existing administrative offences defined in the Market Abuse Directive (e. g. transaction, order or other conduct related to the financial instrument; a commissive conduct) $\underline{13}$, the regulation covers also omissions and measures to prevent specific transactions (omissive conduct). 14

6. A rebuttable presumption - so called interpretive rule to assess unlawful conduct $\underline{15}$ - has been formally established which was already formulated by the decision-making practice of the European Court of Justice in the context of the previous directive.16 It refers to objectivization of the conduct, which means that it is assumed that the conduct of a legal or natural person who is in possession of inside information is forbidden from using inside information, thus an unlawful conduct. However, a rebuttable presumption fully respects the preservation of the rights of defense. The respective recital 17 extends the interpretive rule also to all subsequent changes to orders that were placed before possession of inside information, including the cancellation or amendment of an order, or an attempt to cancel or amend an order. In practice it will mean that within the sanction proceedings the commitment of the offence of insider dealing will be always presumed until proven otherwise by the person against whom the sanction proceedings are conducted (reversed burden of proof).

7. When committing market manipulation, an attempt to engage in market manipulation 18 , which was originally covered under the MAD only in relation to the second form of market abuse (insider dealing) shall be also deemed unlawful.

Changes pursuant to item 5,6 and 7 present a significant and a stricter legislation, extensively defining market abuse. Based on this, it will be possible to sanction an unlawful conduct, the assessment of which was disputed or could not be at all considered as one of the forms of market abuse in the past.

8. Insider dealing in the form of tipping (recommendation, abetting to trading based on a 'good tip' for investment) will be examined in the context of subjective elements - the knowledge that it is an inside information and the conduct is based thereon. Recommendation and abetting will be considered separately as an unlawful conduct, under the definition of unlawful disclosure of inside information.

9. General exceptions to conducts that are otherwise deemed market abuse were directly reflected in the regulation (buy-back programmes and price stabilization, etc.).19 Moreover, the regulation extended the activities and entities which will not fall under the regulation due to public interest:

- transactions carried out by the European Commission or any other officially designated body acting on its behalf in pursuit of public debt management policy;

- transactions carried out by the European Commission, special purpose vehicle of one or several Member States, European Investment Bank, European Financial Stability Facility, European Stability Mechanism, an international financial institution established by two or more Member States which has the purpose to mobilize funding and provide financial assistance to the benefit of its members (especially the Single Resolution Board managing the supranational Single Resolution Fund) 20 ;

- activity of the Member States, European Commission or any other officially designated body acting on their behalf, which concerns emission allowances and which is undertaken in pursuit of the climate policy or in pursuit of the common agricultural or fisheries policy $\underline{21}$.

The general exceptions do not apply to employees or external collaborators of the aforementioned entities (e. g. employee of the Agency for Debt and Liquidity Management) under the conditions that the given natural persons carry 
out prohibited transactions, directly or indirectly, on their own account, or they engage in prohibited behaviour in form of aiding and abetting. However, national legislations should, in our opinion, implement such organizational measures that would restrict market abuse by the said natural persons.

In addition to the original special exceptions to unlawful conducts (e. g. legitimate conduct of market makers, persons authorised to act as counterparties, persons authorised to execute orders on behalf of third parties, takeover bids, etc.), the regulation distinguishes some new special exceptions (behaviour on the basis of own trading plans and strategies, market soundings $\underline{22}$ if the relevant market lacks confidence). Some of the existing special exceptions are directly adopted in the text of the regulation 23 , not only in the recitals as in MAD.

10. The Market Abuse Directive did not set forth the obligation of a legal entity to implement organisational measures to restrict dissemination of inside information. The implementation thereof deprives the legal entity that is in possession of inside information of the mentioned rebuttable presumption that it used the inside information. The regulation, directly in its text, requires the implementation of the aforementioned measures.

11. For market manipulation the merits of dissemination of false information is complemented by dissemination of misleading information or provision of false inputs in relation to a benchmark, or any other behaviour which manipulates the calculation of a benchmark. $\underline{24}$

The regulation's non-exhaustive list of examples of manipulative behaviour includes placing orders, cancellation or modification thereof by any and all available means of trading. Specifically this is an algorithmic and high-frequency trading if it is executed with certain negative effect on the market.25 The algorithmic and high-frequency trading is considered as one of the potential risk carriers, including manipulative practices. The requirement of its regulation refers to the requirement of MiFID II for risk control at investment firms which use this method of trading.26 However, the regulation also underlines the importance of various internet applications and their impact on the investor's behaviour (blogs, social networks like facebook) and points out the necessity of putting them on an equal footing with traditional dissemination of information. The non-exhaustive list of market manipulation indicators was transferred from Directive 2003/124/EC implementing MAD to Annex I of the regulation. MAR, however, emphasises that it is only a nonexhaustive list of indicators relating to false or misleading signals and to price positioning (Part A, Annex I) and a nonexhaustive list of indicators relating to the employment of a fictitious device or any other form of deception or contrivance (Part B, Annex I).

12. In addition to the national supervisory authorities, also a supranational supervisory authority, namely the European Securities and Markets Authority (ESMA), is involved in the process of accepted market practices (AMPs). The national supervisory authority, which is the Národná banka Slovenska (National Bank of Slovakia) in the Slovak Republic, will have to before establishing an accepted market practice notify ESMA of the intention to establish an accepted market practice at least three months before the AMP is intended to take effect. Following this notification, ESMA shall issue an opinion assessing the compatibility of the AMP with the criteria under the regulation, and whether the establishment of the respective AMP would not threaten the market confidence. Where a national supervisory authority establishes an accepted market practice contrary to the opinion of ESMA, it shall publish on its website a notice setting out its reasons for doing so. Such procedure should facilitate market transparency and functioning of small capital markets to which the relevant market practice should not necessarily present a threat as in the case of more developed capital markets. At the same time, it will help avoid arbitrariness of procedures of national authorities according to the principle 'comply and explain'.

13. The regulation assumes establishment of effective precautionary measures, systems and procedures aimed at preventing and detecting insider dealing, market manipulation and attempts thereof under the threat of administrative sanctions for operators of regulated or non-regulated markets (MTF, OTF). These are requirements for the operators of these markets not for market participants.27 In practice, it will more probably refer to technical software requirements and requirements to carry out orders related to transactions. The details should be laid down in the implementing technical standards of ESMA.

14. A number of changes were made within the obligation of disclosure of inside information (ad hoc publicity). One of them is ad hoc publicity of inside information related to financial instruments that are admitted to trading on an SME growth market ('small and medium enterprises'). The respective inside information may be posted on the website of the respective market instead of on the issuer's website where such facility, based on the decision of the market operator, is provided to SME issuers. 28 By the effect of embedding this simplified way of information reporting, the administrative burden for the issuers on the markets of small and medium enterprises should be reduced. In order to preserve the stability of the financial system 29 , the regulation introduced a special reason for delaying the performance of the ad hoc publicity obligation for selected issuers. Specifically, it refers to financial institutions and credit institutions where inside 
information is related to their temporary liquidity problems (for example, the need to receive temporary financial assistance from a central bank as lender of last resort). The delay may be executed with a time limit provided that the following conditions are met cumulatively: 30

- the disclosure of the inside information entails a risk of undermining the financial stability of the issuer and of the financial system;

- it is in the public interest to delay the disclosure;

- the confidentiality of that information can be ensured;

- the competent authority has consented to the delay.

Provided that consent to delay the disclosure is not granted by the competent authority, the issuer must disclose the information without delay. The introduction of the special reason is closely related to the second pillar of the EU's Banking Union (crisis management and resolution). 31

15. The regulation introduces exemption from the obligation to draw up an insider list for issuers of financial instruments admitted on the SME market. This is an unburdening approach in order to reduce the administrative costs arising from this obligation for SMEs. 32 We see this initiative as a psychological effect not to discourage starting smalland medium-sized issuers with various administrative obligations which are connected with issuance and subsequent trading in financial instruments. However, the supervisory authority may request for provision of an insider list. Therefore, small- and medium-sized issuers will have to be able to develop an insider list upon request and provide it. Moreover, the obligation to instruct persons with access to inside information remained for all the issuers. With respect to the archiving obligation of the issuers, the period to retain all inside information on their websites has been prolonged (from one year to at least five years).

16. The notification of managers' transactions (transactions of persons discharging managerial responsibilities at the issuer and transactions of persons closely associated with them) has been significantly extended. The obligation of notification refers not only to transactions relating to shares admitted to a regulated market or their derivatives, but also to transactions relating to debt instruments and/or all financial instruments to which the regulation subject will apply (it means also emission allowances, financial instruments on OTF and MTF). At the same time, the regulation shortened the notification period for the managers' transactions, i. e. from five days to three days. The obligation of notification of managers' transactions was complemented by pledging and lending of financial instruments as the given legal operations can result in a material and potentially destabilizing impact on the issuer. 33 The regulation rationalized the aforementioned addition of pledging and lending as follows, 'without disclosure, the market would not know that there was the increased possibility of, for example, a significant future change in share ownership, an increase in the supply of shares to the marketplace or a loss of voting rights in that company'.34

17. The previous European legislation under MAD did not set forth any specific rules for cooperation between the relevant national supervisory authorities and ESMA. Therefore, the regulation explicitly constituted the mutual relations between the aforementioned authorities in the form of cooperation (in exchange of information, investigation of market abuse forms, on-site inspection, and recovery of imposed pecuniary sanctions). 35 In terms of the regulation, ESMA is in the position of a coordinator of investigation in cases with cross-border effects if it is requested by one of the involved national supervisory authorities. The cooperation in the form of investigation and on-site inspection may be executed in several ways:

- the requested national authority may carry-out the on-site inspection or investigation itself;

- it may allow the requesting party to participate in an on-site inspection or investigation;

- allow the requesting party to carry out the on-site inspection or investigation itself;

- appoint auditors or experts to carry out the on-site inspection or investigation;

- share specific tasks related to supervisory activities with the other competent authorities. 36

Supervisory authorities of third countries (non-EU countries) may also take part in cooperation provided that cooperation arrangements concerning the exchange of information and the enforcement of obligations arising under MAR are concluded with them.

18. Specifically it is necessary to draw attention to the specific legislation of whistleblowing for reporting of market abuse behaviours. 37 In this respect, the regulation puts greater emphasis on the protection of persons reporting infringements of the provisions concerning prohibitions and obligations. Reporting should be carried out within a reporting mechanism to a national supervisory authority. $\underline{38}$ At the same time, according to the regulation, member states should be allowed to provide for financial incentives for whistleblowers.

\section{Conclusion}


Most of the MAR provisions came into force on 3 July 2016 (some provisions have been applied since 2 July 2014; provisions related to OTF, SME markets, emission allowances will apply only from 4 January 2017). In compliance with the principle of direct applicability of the European regulation, the national supervisory authorities throughout the entire European Economic Area must, therefore, adopt the relevant provisions of the regulation starting from the mentioned date. The relevant national provisions governing the whole issue of market abuse (insider dealing and market manipulation) were repealed in the Slovak Republic by amending the Act on Securities and Investment Services effective from 1 July 2016.39 In compliance with Article 144, Paragraph 3 of the Act on Securities and Investment Services, the sanctions for market abuse shall be imposed directly in terms of the regulation. 40 With respect to the scope and significance of changes introduced by MAR, it appears to be optimal that the national legislation was omitted and not replaced. Adoption of own national legal provisions into the Act on Securities and Investment Services would bring a risk that its wording could be in contradiction with the wording of the regulation. Despite the effort of the legislator, it can be stated that not all areas of the MAR legislation were fully implemented. The regulation related to whistleblowing in relation to market abuse has not been amended in details on national level despite the fact that the implementing directive to the regulation $\underline{11}$ that should harmonize the legal regulations in this area determined 3 July 2016 as the date of its transposition. Although the Slovak Republic has a general legislation on reporting of anti-social behaviour (under the Whistleblowing Act) since 1 January 2015, it has chosen an approach of special legislation for whistleblowing in relation to all unlawful behaviours on the entire financial market, not only in relation to market abuse. This approach was reflected in a bill amending the financial market supervision act - a basic procedural regulation for the entire financial market. The reason is the effort to exclude differences in the application practice in relation to various financial market entities. Although, we consider that the aforementioned approach is appropriate, but its legislative process has been significantly falling behind as the transposition of the implementing directive should have taken place already on 3 July 2016 (only in relation to reporting of market abuse). The duration of the legislative process is in this case to the detriment of effective reporting of suspicious transactions of insider dealing or market manipulation. With respect to the fact that these are hardly detectable and provable unlawful conducts, the absence of a detailed whistleblowing process can be deemed negative which makes it impossible to effectively enforce the provisions of the regulation despite the fact that the Slovak Republic had repealed the national legislation in time due to conflict. At the same time, most of the changes introduced by MAR and listed in the text above will not be applicable in the Slovak Republic given the small volume of the Slovak capital market.

\section{References}

1 Directive 2003/6/EC of the European Parliament and of the Council of 28 January 2003 on insider dealing and market manipulation (market abuse); Market Abuse Directive (hereinafter MAD).

2 Communication from the Commission to the European Parliament, the Council, the European Economic and Social Committee and the Committee of the Regions, dated 8 December 2010, on Reinforcing Sanctioning Regime in the Financial Services Sector.

http://ec.europa.eu/smart-regulation/impact/ia carried out/docs/ia 2010/com 20100716 en.pdf (accessed 7 Feb. 2015)

3 Regulation No. 596/2014, dated 16 April 2014, on market abuse (market abuse regulation) and repealing Directive 2003/6/EC of the European Parliament and of the Council and Commission Directives 2003/124/EC, 2003/125/EC and 2004/72/EC; Market Abuse Regulation (hereinafter MAR).

4 Directive 2014/65/EU of the European Parliament and of the Council of 15 May 2014 on markets in financial instruments; Markets in Financial Instruments Directive II (hereinafter MiFID II). Its transposition was postponed from the original date of 3 July 2016 to 3 July 2017 due to the complexity of the legislation.

Updated rules for markets in financial instruments: MiFID 2,

http://ec.europa.eu/finance/securities/isd/mifid2/index en.htm (accessed on 14 Aug. 2016).

5 Libor Klimek, Effective Enforcement of Sanctions for Market Abuse in the EU: Introduction of Criminal Sanctions, 114, in Alexander Bělohlávek, Filip Černý \& Naděžda Rozehnalová (eds.), Regulatory Measures and Foreign Trade, Czech Yearbook of International Law (Juris Publishing, Inc., Huntington, New York, 2013). https://doi.org/10.2139/ssrn.2624110 
$\underline{6}$ For instance, Husták was engaged in the issue of innovations introduced by MAR. Zdeněk Husták, The New Market Abuse Regulation - torrent of duties in midsummer, http://www.epravo.cz/top/clanky/nove-narizeni-o-zneuzivani-trhuzaplava-povinnosti-v-parnem-lete-101826.html (accessed on 14 Aug. 2016).

7 See titles of articles 8, 10, 12, 14 and 15 of MAR or Recital 7 of MAR.

$\underline{8}$ OTF is considered as another alternative trading platform to the regulated market, which will be deemed a new investment service and it will fall under the legal regulation of MiFID II. Refer to definition under Art. 4, para. 1, item 23 of MiFID II.

2 Refer to Art. 2, para. 1 and Recital 8 and 9 of MAR.

10 Refer to Recital 39 of MAR.

11 Directive 2004/39/EC of the European Parliament and of the Council of 21 April 2004 on markets in financial instruments.

12 A serious case of a multiannual manipulation of benchmarks was the scandal related to the manipulation of LIBOR interbank rate which influenced the US market too.

13 Regardless the fact whether it was conducted on a trading venue or as a non-public trading.

14 Refered to Recital 23 of MAR 'prohibition against insider dealing should apply where a person who is in possession of inside information takes unfair advantage of the benefit gained from that information by entering into market transactions in accordance with that information, or by cancelling or amending, or by attempting to cancel or amend an order to acquire or dispose of ... '. Cf also Art. 8, para. 1 of MAR.

15 To be found under Recital 23 and 24 of MAR.

16 Preliminary ruling proceedings before the European Court of Justice in Case No. C-45/08 Spector Photo Group NV, Chris Van Raemdonck v. Commissie voor het Bank-, Financie- en Assurantiewezen (CBFA). Refer to the ruling of the European Court of Justcie in this case dated 23 December 2009, http://eur-lex.europa.eu/legalcontent/EN/TXT/HTML/?uri=CELEX:62008CJ0045\&qid=1472221177998\&from=SK (accessed on 14 Aug. 2016).

17 Recital 25 of MAR.

18 The reasoning of this objective is indicated under Recital 41 of MAR and it assumes that market manipulation was not completed as a result of failed technology, but the seriousness of this conduct is equally important.

19 Refer to Art. 5 and 6 of MAR. For buy-back programmes and price stabilization refer to Lubomír Čunderlík, Market Transparency and Capital Market Abuse, 126-140 (Wolters Kluwer, Bratislava, 2015).

$\underline{20}$ For these entities refer to L'ubomír Čunderlík, Financial Implications of Mandatory Contributions of Bank Entities in Times of Financial Crisis in the Context of Banking Union Anticipation, 31-50 in Damian Czudek, Michal Kozieł (eds.), Legal and Economic Aspects of the Business in V4 Countries, Conference proceedings (Tribun EU, Centrum Prawa Polskiego, Brno, 2014).

21 Recital 13, 21 and 22 of MAR.

22 Art. 11 of MAR. In practice, it can be a situation known as 'road show', when the issuing manager contacts key investors and provide them the trade conditions. The execution of market sounding will be considered as a lawfully authorised disclosure of inside information in the course of exercise of that person's employment or function, if the person disclosing the information in this way fulfills the requirements under Art. 11, paras 3 and 5 of MAR.

23 For instance, Art. 9 of MAR.

24 Art. 12, para. 1 d) of MAR.

25 Art. 12, para. 2 c), items I to III of MAR.

$\underline{26}$ Art. 17 of MiFID II.

27 The requirement is based on the parallel requirements determined under Articles 31 and 54 of MiFID II.

$\underline{28}$ Art 17, para. 9 of MAR. 
29 Stated under Recital 52 of MAR: '... the wider public and economic interest in delaying disclosure outweighs the interest of the market in receiving the information which is subject to delay.'

30 Pursuant to Art. 17, para. 5 of MAR.

31 Refer to Recital 64 and Art. 39, para. 2 of Directive 2014/59/EU of the European Parliament and of the Council of 15 May 2014 establishing a framework for recovery and resolution of credit institutions and investment companies; Bank Recovery and Resolution Directive (BRRD).

32 Refer to the reasoning under Recital 56 of MAR.

33 The interpretation of the previous legislation of MAD was not uniform. Despite that, already before the adoption of MAR, there were opinions criticising this imperfection of MAD. Refer to, for example Josef Kotásek, Managers' Transactions, 128 in Josef Bejček (ed.), Veřejný zájem v obchodním právu, Conference proceedings (Masarykova Univerzita, Brno, 2008).

\section{Recital 58 of MAR.}

35 A national supervisory authority may refuse a request to cooperate only under the exhaustively listed conditions. See Art. 25, para. 2 of MAR.

36 These forms of cooperation are broader than those that are indicated under Art. 16, para. 4 of MAD.

37 By the effect of adopting Whistleblowing Act No. 307/2014 Coll. in the Slovak Republic with effect from 1 January 2015, the protection of whistleblowers in relation to defined criminal offences and administrative offences was introduced already before the regulation entered into force. The regulation, however, presents a special legislation for reporting illicit conduct on the capital market.

38 Implementing Directive (EU) 2015/2392 of 17 December 2015 as regards reporting to competent authorities of actual or potential infringements of MAR lays down details on whistleblowing procedures before national supervisory authorities set out in Art. 32 para. 1 of MAR. Its provisions shall apply from 3 July 2016. In the Slovak Republic, the details of this mechanism will be adjusted both by an act amending the act on financial market supervision (with proposed effect from 1 October 2016) and by internal work regulation of the Národná banka Slovenska (National Bank of Slovakia). The bill amending the act on financial market supervision is currently under late interdepartmental review, and its original date of effect was determined for 3 July 2016 (identical to both regulation $\Phi_{s}$ and implementing directive's date of effect).

39 Act No. 361/2015 Coll. dated 10 November 2015 amending Act on Securities and Investment Services. Its entry into force repealed Art. 131a up to Art. 132n and Art. 144, para. 12.

$\underline{40}$ Art. 30, para. 2 and Art. 31 of MAR.

41 Implementing Directive (EU) 2015/2392 of 17 December 2015 on MAR as regards reporting to competent authorities of actual or potential infringements of that Regulation. 